\title{
Acidosis tubular renal
}

\author{
Drs.: C. Saieh* - F. Puga* - E. Rodríguez*
}

El estudio de la acidosis tubular renal (A.T.R.) comienza en el año 1935, cuando Lightwood describe 6 casos, encontrados en 850 autopsias de acidosis de etiología incierta. Desde entonces a la fecha se han realizado múltiples estudios tendientes a esclarecer la etiología, mejorar el diagnóstico y tratamiento $y$ clasificar en forma más lógica cada una de sus variedades. Lamentablemente para el clinico general este capítulo de la medicina es cada vez más incomprensible, lo que nos motivó a hacer esta presentación pretendiendo clasificar lo que es y significa la A.T.R.

El hombre y otros mamíferos regulan el metabolismo ácido-básico en un preciso y muy exacto rango, manteniendo equilibrada la concentración de hidrogeniones en el plasma; y es el riñón el órgano capaz de jugar tan importante papel, a través de la regulación de bicarbonato y de la excreción de hidrogeniones producidos endógenamente, aproximadamente 2 a $3 \mathrm{mEq}$ en la infancia por kilo de peso en 24 horas.

En la A.T.R. estos mecanismos están alterados, produciéndose una acidosis metabólica con uremia o creatinina en sangre, normal. Podemos definirla como un síndrome clínico en el cual existe un defecto en la reabsorción tubular de bicarbonato y/o en la habilidad para mantener un gradiente de hidrogeniones normales entre el plasma y la luz tubular. Desde el punto de vista bioquímico se caracteriza por una baja concentración de bicarbonato sérico, hipercloremia y un $\mathrm{pH}$ urinario alto.

Para comprender mejor lo que sucede, veremos primero cómo el organismo es capaz de regular el metabolismo ácido-básico y luego cuáles son las funciones específicas del túbulo renal.
El pulmón cumple una función importante tratando de conservar la neutralidad de los líquidos corporales, pero el riñón es el único que puede regular el balànce de los $\mathrm{H}$, siendo el $70 \%$ de estos iones proveniente del catabolismo de las proteínas, aunque en el niño una cantidad muy importante proviene del metabolismo óseo, la función reguladora la cumple a través de tres mecanismos:

- Reabsorción del bicarbonato filtrado.

-Excreción de acidez titulable, o sea los iones hidrógenos unidos a los tampones, principalmente fosfatos.

- H captados por el amoniaco, o dicho en otras palabras, a través de la excreción de amonio $\left(\mathrm{NH}_{4}\right)$.

Estas tres funciones son independientes, pero suceden en un mismo momento.

El bicarbonato es reabsorbido casi en su totalidad en el túbulo proximal y esto depende en lo fundamental de su concentración en el plasma. Es así que el transporte máximo de bicarbonato corresponde entre 26 a $28 \mathrm{mEq}$ por litro de concentración plasmática.

El bicarbonato de sodio filtrado puede considerarse disociado en sodio y bicarbonato. El sodio del filtrado glomerular es intercambiado por hidrógeno en la célula tubular. El hidrógeno secretado activamente se combina en la luz tubular con bicarbonato, dando origen al ácido carbónico, que se disocia fácilmente en $\mathrm{CO}_{2}$ y $\mathrm{H}_{2}$ 0. El $\mathrm{CO}_{2}$ difunde rápida y pasivamente la célula tubular y en ésta, en combinación con $\mathrm{H}_{2} \mathrm{O}$ y bajo la acción de la anhidrasa carbónica se transforma en ácido carbónico, disociándose luego en hidrógeno y bicarbonato. El hidrógeno es excretado al lumen, como ya se indicó anteriormente, y el bicarbonato se recombina con el sodio reabsorbido y difunde pasivamente como bicarbonato de sodio al plasma. 
EXCRECION DE HIDROGENO: El pH urinario puede descender hasta 4.4. Cuanto más bajo es el pH urinario mayor es la cantidad de hidrógeno que se combina con los buffers filtrados (fosfatos, creatinina, etc.) y mayor es la cantidad de amonio producido por la célula tubular. a) Acidez titulable: de los buffers presentes en la orina el más importante es el fosfato, ya que actúa en el túbulo distal, dado que el bicarbonato ha sido reabsorbido casi en su totalidad en el túbulo proximal. b) Amonio es producido en el túbulo colector y difunde pasivamente al filtrado. Este proviene de la desanimación de la glutamina por la glutaminasa. Cabe hacer notar que al nivel que actúa la excreción de hidrogeniones es competitiva con la eliminación de potasio y con la reabsorción del sodio.

En resumen: la cantidad total de hidrógeno excretado es igual a la suma de moléculas ácidas (acidez titulable) y de amonio menos los bicarbonatos de la orina.

Veremos ahora qué pasa en los túbulos. En el glomérulo se produce un ultrafiltrado plasmático con un contenido de no más de $50 \mathrm{mg} . / 100 \mathrm{ml}$. de proteínas, que se ofrece al túbulo renal, donde se modifica su volumen, composición y concentración, para ser eliminado a través de los colectores, uréter, vejiga y uretra hacia el exterior, con las características de la orina por todos conocidas.

Experimentalmente se ha determinado la función de cada fragmento del túbulo por medio de la micropunción y de la diuresis interrumpida y es así como podemos establecer claramente las siguientes funciones:

1. Túbulo proximal: Reabsorción del $80 \%$ del volumen filtrado.

- Reabsorción del $90 \%$ de sodio, cloro, bicarbonato y fosfato y la casi totalidad de los aminoácidos, calcio, potasio, proteínas y glucosa.

2. Túbulo distal: Reabsorción de agua de acuerdo a las necesidades del organismo.

- Acidificación urinaria.

— Concentración y dilución de la orina.

Clínicamente puede presentarse de muchas maneras, siendo las más importantes la acidosis metabólica sin causa conocida y acompañada por $\mathrm{pH}$ en orina con tendencia a la alcalinidad, falla en el crecimiento, trastornos gastrointestinales, deshidrataciones frecuentes, poliuria, polidipsia o vómitos.
Varias etiologías se han dado a través del tiempo, aunque ninguna ha sido demostrada fehacientemente como verdadera, por lo que nos limitaremos a mencionarlas.

La A.T.R. proximal se dice que es un defecto transitorio, mientras que la distal tendría un defecto permanente.

Como etiología propiamente tal se plantea el origen hereditario autosómico dominante, la posibilidad que sea una enfermedad autoinmune o también con trastornos primariamente metabólicos; además se ha mencionado el déficit de potasio y por último disminución de la actividad de la anhidrasa carbónica.

Tuvieron que pasar 30 años para que Soriano y colaboradores basándose en la fisiopatologia sugirieran separar la A.T.R. en 2 tipos distintos: la proximal y la distal.

En la A.T.R. proximal hay un defecto en la reabsorción de bicarbonato con preservación de la capacidad para excretar iones hidrógeno libre o combinados, con predominio en el sexo masculino y comienzo en los primeros meses de vida.

La A.T.R. distal está definida por la ausencia de capacidad del túbulo para establecer un gradiente de hidrogeniones entre la sangre y la orina tubular, con un franco predominio por el sexo femenino.

También se les puede clasificar en genéticas y adquiridas, siendo estas últimas las más frecuentes, por ejemplo la nefritis intersticial y la pielonefritis, pero nosotros solamente nos referiremos a las tubulopatías no adquiridas.

Estas últimas pueden dividirse en primarias, cuando no hay evidencia de enfermedad sistémica o compromisos de otros sistemas, y secundarias.

A continuación damos una clasificación de acuerdo a la fisiopatología y en forma simplificada.

\section{ACIDOSIS TUBULAR RENAL PROXIMAL}

- Primaria:

- Secundaria: 


\section{ACIDOSIS TUBULAR RENAL DISTAL}

- Primaria

- Secundaria:

Pielonefritis

Hipergamaglobulinemia

Intoxicación por vitamina $\mathrm{D}$

Hipercalciuria

- Con 5 a $10 \%$ de bicarbonato perdido.

- Híbrida: con inadecuada excreción de ácidos y más de $15 \%$ de pérdidas de bicarbonato.

El diagnóstico puede sospecharse clínicamente, pero debe confirmarse por el laboratorio.

El examen clínico no revela anormalidades la mayoría de las veces, pero en presencia de nefrocalcinosis y/o raquitismo debemos pensar con mayor certeza que se trata de un A.T.R. distal.

El examen de orina nos ayudará en gran magnitud cuando $\mathrm{su} \mathrm{pH}$ ha sido medido en orina recién emitida y con electrodos.

Se debe descartar este examen cuando se utiliza cinta. En caso de tener $\mathrm{pH}$ en orina, recién emitida, menores de 6, podemos descartar la acidosis tubular distal, ya que generalmente, y a pesar de la acidosis metabólica, el pH en orina se encuentra en valores entre 6,5 y 7,5, mientras que la forma proximal presenta un $\mathrm{pH}$ de acuerdo al grado de acidosis metabólica.

El estudio del $\mathrm{pH}$ y $\mathrm{CO}_{2}$ en sangre siempre nos demostrará acidosis metabólica, excepto en las formas incompletas.

El conocimiento del umbral de la excreción renal es muy importante en el estudio de la acidosis tubular distal. Edelman en 1967 propone realizar una sobrecarga con cloruro de amonio con una sola dosis. Esta prueba consiste en dar una dosis única de cloruro de amonio y medición de $\mathrm{pH}$ en orina 3 y 4 horas más tarde. $\mathrm{El} \mathrm{pH}$ y $\mathrm{CO}_{2}$ en sangre se determinan antes y 3 o 4 horas después de ingerida la dosis. Para calcular la dosis se emplea la siguiente fórmula:

$\mathrm{NH}_{4} \mathrm{Cl}(\mathrm{mEq})=$ Peso $(\mathrm{K}) \times 0.6 \times\left(\mathrm{CO}_{2}\right.$ total $)$ inicial $=\left(\mathrm{CO}_{2}\right.$ total buscado $)$.

El amonio y la acidez titulable en orina son normales en la A.T.R. proximal mientras que en la distal están deprimidos.

En la A.T.R. proximal la concentración máxima urinaria es normal en tanto que en el grupo de A.T.R. distal, no es posible alcanzar valores mayores de $500 \mathrm{mOsm} / 1$, así como en ellos también se observa disminución de la filtración glomerular.

El estudio radiológico es generalmente normal, pero nefrocalcinosis se puede observar en los niños con A.T.R. distal, hecho que podría explicarse porque existe retención de iones hidrógeno y como el $\mathrm{CO}_{2}$ total y los buffer permanecen constantes, debe existir un mecanismo extrarrenal para manejar estos hidrogeniones y restablecer los aniones buffer a los fluidos corporales. Este mecanismo reside en los huesos. Además sabemos que $\mathrm{pH}$ persistentemente altos en orina y citratos urinarios bajos facilitan la precipitación del calcio, por lo tanto la hipercalciuria es también característica de la A.T.R. distal, así como el raquitismo.

La bicarbonaturia es alta en la A.T.R. proximal y en la distal puede haber pequeñas cantidades cuando el bicarbonato circulante es alto.

La aminoaciduria y la glucosuria sólo se encuentra alterada en los pacientes portadores de A.T.R. proximal secundarios.

Si bien la mayoría de estos niños no mejoran, un correcto tratamiento los beneficia grandemente, y una vez iniciada la terapia alkalinizante mejora el crecimiento y su estado general, pudiendo realizar una vida totalmente normal, debiendo controlarse más o menos cada 6 semanas con el fin de ajustar las dosis. Los síntomas atribuibles a hipokalinemia o hipercalcemia son raros. La dosis para mantener niveles de bicarbonato normales en el plasma son marcadamente diferentes en los dos grupos, a causa de que la fisiopatología subyacente es también diferente.

Los pacientes con acidosis tubular proximal requieren como mínimo 10 a $15 \mathrm{mEq} / \mathrm{kg}$. en 24 horas de bicarbonato, mientras que aquellos con acidosis distal necesitan sólo 2 a $3 \mathrm{mEq} / \mathrm{kg}$. en 24 horas.

Finalmente y si no queremos cargar sobre nuestras espaldas la culpabilidad de una nefropatía crónica, una detención del crecimiento, un desnutrido e invalidado permanente, o por último el fallecimiento de un niño, realizamos un completo estudio frente a un paciente en el que sospechamos una acidosis tubular renal.

Como conclusión presentamos un cuadro resumen explicativo de la acidosis tubular renal. 


\section{PROXIMAL}

- Defecto transitorio?

-Predominio sexo masculino.

- Inicio en los primeros meses de la vida.

-Defecto reabsorción bicarbonato.

$-\mathrm{pH}$ en orina $<5.3$ con prueba de cloruro amonio.

$-\mathrm{CO}_{2}$ en sangre: bajo

-Amonio y acidez titulable normal.

-Concentración máxima urinaria normal.

-Flujo renal normal.

-Radiografias normales.

-Bicarbonaturia alta.

- Aminoaciduria alterada.

-Tratamiento: 10 a 15 $\mathrm{mEq} / \mathrm{kg} . / 24$ hrs. de Bicarbonato.

\section{DISTAL}

- ¿Defecto permanente?

-Predominio sexo femeninino.

-Inicio más tardío.

-Incapacidad para manejar $\mathrm{H}^{-}$.

$-\mathrm{pH}$ en orina nunca $<5.3$ con prueba de cloruro de amonio y sobre 6 sin sobrecarga.

$-\mathrm{CO}_{2}$ en sangre: bajo

-Amonio y acidez titulable: valores bajos.

-Concentración máxima no mayor de $500 \mathrm{mOsm} / \mathrm{l}$.

-Flujo renal disminuido.

-Nefrocalcinosis y/o raquitismo.

-Bicarbonaturia normal.

-Aminoaciduria normal.

-Tratamiento: 2 a $3 \mathrm{mEq} /$ kg./24 hrs. de bicarbonato.

\section{REFERENCIAS}

${ }^{1}$ Ped. Clinic of N.A. - Nov. 1976.

2 Ped Clinic of N.A. - May. 1971.

3 Disease a Month - March 1977. Vol. XXIUI Number 6. Year Book Medical Publishers. Inc. Chicago.

4 Renal Diseases in Childhood - J. James - 1974 - The C.U. Mosby Company - Saint Louis.

5 Nash M. Torrado A., Greifer I. et al. J. of Pediatrics - 80, 738, 1969
${ }^{6}$ Curtis Morris. The New Eng. J. of Med. - 281, 1405, 1969.

7 Hirschman G. Rao D., Oyenade O. - Clinical Ped. - 15, 645, 1976.

8 Graziani G., De Vecchi D. - Helv. Pasd. Acta - 31, 427, 1976.

9 O'Brien D. - Butterfield L. - Arch. Dis. Childh. - 38, 437, 1963.

10 Rodriguez-Soriano J. Boichis H. Edelman C.M. - 71, 802, 1967.

11 Lightwood. R. et al. Pediatrics. - 12, 628, 1953. 